\title{
Teología del Cuerpo Místico, antropología y moral social en san Alberto Hurtado. La influencia de Columba Marmión ${ }^{1}$
}

\author{
Cristián Hodge \\ FACULTAD DE TEOLOGÍA \\ PONTIFICIA UNIVERSIDAD CATÓLICA DE CHILE
}

El estudio académico sobre el padre Hurtado ha tenido avances en estos últimos años. Distintos autores, como Samuel Fernández, Tony Mifsud y Fredy Parra, han destacado la relevancia de la teología del Cuerpo Místico de Cristo en el pensamiento de san $\mathrm{Alberto}^{2}$. Por otra parte, Patricio Miranda ha considerado el libro Moral Social del padre Hurtado como un hito en la constitución disciplinar de la moral social desde América Lati$n a^{3}$. En este contexto, el presente artículo ${ }^{4}$ pretende mostrar que nuestro autor desde la teología del Cuerpo Místico desarrolló una comprensión del hombre que llegó a ser el fundamento antropológico de su moral social. San Alberto pensó lo social desde categorías teológicas proporcionadas por la doctrina del Cuerpo Místico de Cristo. En una primera parte, se

Este trabajo se ha valido de los avances del proyecto Fondecyt 1090033 (2009/2010).

2 Cf. S. FERNÁNDEZ, «¿Reformar al individuo o reformar la sociedad? Un punto central en el desarrollo cronológico del pensamiento social de san Alberto Hurtado», Teología y Vida, XLIX (2008) 524; T. Mifsud, El sentido social: el legado ético del padre Hurtado (Santiago 2005) 48-52; F. PArra, «Teología del Cuerpo Místico, Comunión de los Santos y pensamiento social en san Alberto Hurtado. La influencia de Émile Mersch y Karl Adam», Teología y Vida, L (2009) 797-835.

3 Cf. Miranda, «Preludios del aggiornamento de la Moral Social en América Latina», Moralia, XXXI (2008) 159-184.

4 Este artículo muestra parte de los resultados de la investigación C. Hodge, El Cuerpo Mistico de Cristo y sus consecuencias sociales en san Alberto Hurtado. Una fundamentación antropológica de la moral social. Profesor guía S. FERnÁndez. Tesis para optar al grado de Magíster en Teología Dogmática (Pontificia Universidad Católica de Chile, Facultad de Teología, Santiago de Chile 2009). 
expone el lugar que fue ocupando la teología del Cuerpo Místico en su pensamiento y en los distintos contextos de su apostolado. En segundo lugar, se revisan los aspectos de esta teología que desarrolló nuestro autor en comparación con unos textos de Columba Marmión, una de sus principales fuentes. Por último, se entregan algunas conclusiones de este estudio sobre antropología y moral social en el pensamiento del padre Hurtado.

\section{La importancia de la teología del Cuerpo Mistico de Cristo para san Alberto}

El impacto que la teología del Cuerpo Místico ha causado en Alberto Hurtado y de qué manera ha quedado reflejada en sus escritos se puede estudiar en perspectiva histórica, siguiendo las etapas de su vida según la división que propone Samuel Fernández

\subsection{Formación en la Compañia de Jesús (1923-1935) ${ }^{6}$}

Antes de llegar a continuar sus estudios en Lovaina, Alberto Hurtado encontró en la imagen del Cuerpo Místico una integración tanto del deseo de intimidad con el Señor como del deseo de amar y servir a los demás?.

En Lovaina (1931-1935) encontró un ambiente teológico y espiritual muy cristocéntrico ${ }^{8}$. Jaime Castellón afirma que «la teología del Cuerpo Místico tenía gran acogida por esa misma razón: porque entendía todos los estudios teológicos teniendo a Cristo como centro» ${ }^{9}$ La teología del Cuerpo Místico le proporcionó categorías teológicas y espirituales que lo marcaron profundamente ${ }^{10}$. Entre los autores de la teología del Cuerpo Místico de Cristo que más

5 Cf. S. FernÁNDEZ, «¿Reformar al individuo o reformar la sociedad?», 516.

6 Cf. S. Fernández, Desarrollo cronológico del pensamiento social de san Alberto Hurtado (Pro manuscripto) 4 .

7 Cf. J. CASTELLón, Identificarse con Jesucristo sirviéndolo en su misión. La espiritualidad del Padre Alberto Hurtado Cruchaga, S.J. (1901-1952) (Pro manuscripto, Roma 1996) 32 y 41.

8 Cf. F. Parra, «Teología del Cuerpo Místico, Comunión de los Santos y pensamiento social en san Alberto Hurtado. La influencia de Émile Mersch y Karl Adam», 799-800.

9 J. CASTELLón, Identificarse con Jesucristo sirviéndolo en su misión. La espiritualidad del Padre Alberto Hurtado Cruchaga, S.J. (1901-1952), 47.

10 Cf. J. CASTELLón, Identificarse con Jesucristo sirviéndolo en su misión. La espiritualidad del Padre Alberto Hurtado Cruchaga, S.J. (1901-1952), 65. 
influyeron en este tiempo en san Alberto se encuentran Columba Marmión $^{11}$, Émile Mersch y Karl Adam ${ }^{12}$.

La teología de Dom Marmion tiene como eje central a Dios que nos hace hijos adoptivos suyos en Jesucristo. Por esto se afirma que merece el título de «Doctor de la adopción divina» ${ }^{13}$. La visión teológica del Abad de Maredsous es: «el plan primitivo de la Trinidad era hacer al hombre a su imagen y semejanza; después de la caída, Cristo se ha convertido en el centro del plan divino; por su Encarnación, El ha expandido a la bumanidad la gracia que tenía como Hijo, por la fe y los sacramentos $\rangle^{14}$. El libro que más impresionó a san Alberto es Cristo, vida del alma. Reconoce explícitamente en Humanismo Social y Conferencia en Cochabamba que se inspira en este libro de Dom Marmion ${ }^{15}$.

\subsection{Apostolado pedagógico (1936-1940)}

A su regreso a Chile, san Alberto se dedicó principalmente a dar clases y a escribir sobre temas pedagógicos. En relación con la teología del Cuerpo Místico de Cristo, se puede encontrar una alusión en su libro La crisis de la pubertad y la educación de la castidad ${ }^{16}$ :

las ideas fundamentales del dogma del Cuerpo Místico de Cristo, cómo todos los cristianos somos solidarios, cómo nuestras buenas acciones aprovechan a todos los hombres y merecen gracias especiales de Dios, y cómo por el contrario el pecado es no sólo un mal individual, sino también un mal social ${ }^{17}$.

11 Dom Columba Marmion (1858-1923) nació en Irlanda. Siendo sacerdote diocesano sintió la vocación benedictina e ingresó al monasterio de Maredsous (Bélgica) en 1886. Prior, profesor de Teología y director espiritual alcanza gran prestigio como teólogo. En 1909, Dom Marmion fue elegido Abad de Maredsous. Fue beatificado el año 2000.

12 Fredy Parra ha estudiado la influencia de E. Mersch y de K. Adam en el pensamiento social de san Alberto Hurtado: cf. F. PArra, «Teología del Cuerpo Místico, Comunión de los Santos y pensamiento social en san Alberto Hurtado. La influencia de Émile Mersch y Karl Adam», 797-835.

13 M. M. Philipon, La doctrine spirituelle de Dom Marmion (Paris 1954) 309.

14 J. CASTELlón, Identificarse con Jesucristo sirviéndolo en su misión. La espiritualidad del Padre Alberto Hurtado Cruchaga, S.J. (1901-1952), 51.

15 Cf. A. Hurtado, Humanismo Social, (Santiago 1947) 28; A. Hurtado, Cuerpo Místico: Distribución y uso de la riqueza, 1950, Archivo Padre Hurtado (APH) s24y09 en A. HurTADO, La buisqueda de Dios (Santiago ${ }^{22005)} 150$.

16 A. Hurtado, La crisis de la pubertad y la educación a la castidad (Santiago 1997).

17 A. Hurtado, La crisis de la pubertad y la educación de la castidad, 69. 
Resulta interesante que el año 1937, antes de la publicación de Mystici Corporis Christi (1943), y en el contexto de su apostolado pedagógico, tenga presente la teología del Cuerpo Místico. San Alberto comenta ideas que desarrollará en sus escritos sociales posteriores: la solidaridad a partir del Cuerpo Místico y la repercusión en «todos los hombres» tanto de las acciones buenas como del pecado. Por otra parte, se refiere al pecado como «mal sociab». Tony Mifsud destaca esta intuición de nuestro autor que será más tarde explicitado por el Magisterio y la moral social al hablar de pecado social o de pecado estructural ${ }^{18}$.

\subsection{Asesor de la Acción Católica (1941-1944)}

El 29 de junio de 1943, el Papa Pío XII publicó la encíclica Mystici Corporis Christi. Este documento pontificio significó para san Alberto un nuevo impulso en el desarrollo de su teología del Cuerpo Místico. El documento pontificio se inserta en la renovación eclesiológica que se desarrolla en los años siguientes a la Primera Guerra Mundial. Jean Frisque afirma que es «la intención [del Papa Pio XII] de resumir los resultados de la renovación eclesiológica durante el periodo que media entre las dos guerras y darles una orientación definitivas ${ }^{19}$.

El 15 de agosto de 1943, a menos de dos meses de la publicación de la encíclica, el padre Hurtado realiza un discurso en el Teatro Caupolicán ante una gran concentración de jóvenes católicos ${ }^{20}$. El tema es el amor al prójimo y su fundamento. Explica la exigencia social del catolicismo y del mandamiento del amor. En este contexto encuentra en la doctrina del Cuerpo Místico el fundamento teológico del amor.

En la Novena de Navidad de ese año 1943, sostiene que la verdad sobrenatural del Cuerpo Místico de Cristo es «la solución a los problemas humanos $\rangle^{21}$. Afirma que la doctrina del Cuerpo Místico de Cristo recuerda «los grandes bienes que nos trajo [el Verbo] con su Encarnación» y que el hombre «está llamado a ser hijo de Dios y que sólo siéndolo llegará a ser plenamente

\footnotetext{
18 Cf. T. Mifsud, El sentido social: el legado ético del padre Hurtado, 89-90, especialmente nota 83 .

19 J. Frisque, «La eclesiología en el siglo XX» en H. Vorgrimler - R. VAnder Gucht (eds.), La teología en el siglo XX, vol. III (Madrid 1973) 169.

20 Cf. $A P H$ s19y27.

21 APH s54y16a.
} 
Teología del Cuerpo Místico, antropología y moral social en san Alberto Hurtado | 589

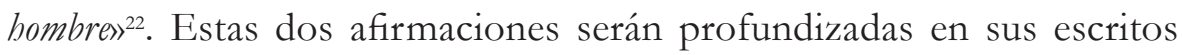
posteriores.

\subsection{Hogar de Cristo y formación social (1945-1947)}

En 1947 publica Humanismo Social. En este ensayo de pedagogía social, quiere fundamentar la actitud social del cristiano. El Cuerpo Místico de Cristo es el fundamento teológico de la caridad ${ }^{23}$. Después de explicar algunos rasgos de esta teología del Cuerpo Místico afirma:

Estas breves ideas son el núcleo de la doctrina del Cuerpo Místico de Cristo y esta doctrina es la llamada a unificar toda la teología católica, como lo decía tantas veces uno de sus más ardiente vulgarizadores, el P. Emilio Mersch S.J. ${ }^{24}$.

\subsection{Moral Social y sentido de Dios (1948-1952)}

En 1950 es invitado a Cochabamba por el episcopado boliviano a participar en la Primera Concentración Nacional de Dirigentes del Apostolado Económico Social. Su conferencia lleva por título Cuerpo Místico: distribución y uso de la riqueza ${ }^{25}$. Esta conferencia marca «un punto de madurez en el pensamiento social del padre Hurtado» ${ }^{26}$. Afirma que la doctrina del Cuerpo Místico de Cristo «ocupa el primer lugar en nuestra posición teo-

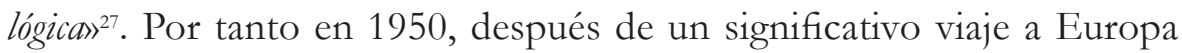

22 APH s54y16a. La cita completa es: «Dirigir al mundo una encíclica recientemente para recordarle al mundo la figura sobrehumana, divina de Cristo, los grandes bienes que nos trajo con su Encarnación y nacimiento, y asi ha publicado la reciente encíclica del Cuerpo Místico de Cristo, que a muchos podrá parecer demasiado sobrenatural, demasiado divina, pero precisamente por serlo es la solución a los problemas humanos, pues si el hombre deja de ser hombre es porque con frecuencia se olvida que está llamado a ser hijo de Dios, y que sólo siéndolo llegará a ser plenamente hombre. En la medida en que el hombre se aleja de su vida divina, se aleja también de sus más nobles y generosos sentimientos y valores humanos) (APH s54y16a).

23 Cf. A. Hurtado, Humanismo Social, 28.

24 A. Hurtado, Humanismo Social, 31. También este texto se encuentra en La orientación fundamental del cristianismo, 1947, $A P H$ s25y04, que es un borrador del capítulo I de $A$. Hurtado, Humanismo Social.

25 APH s24y09.

26 S. FERNÁNDEZ, «¿Reformar al individuo o reformar la sociedad?», 532.

27 A. Hurtado, Cuerpo Místico: Distribución y uso de la riqueza, 1950, APH s24y09 (en A. Hurtado, La búsqueda de Dios, 150). 
(1947-1948)28, la doctrina del Cuerpo Místico sigue ocupando el primer lugar en su teología.

En 1952 al redactar su libro Moral Social, ubica principalmente los textos sobre la teología del Cuerpo Místico de Cristo en la sección dedicada al hombre, en el capítulo sobre los presupuestos de la moral social y en la sección dedicada a la Iglesia, en el capítulo sobre la vida sobrenatural. Por tanto, en su obra póstuma, esta teología sigue ocupando un lugar central en su pensamiento.

\section{La teología del Cuerpo Mistico desarrollada por san Alberto Hurtado}

¿Qué contenidos específicos de esta doctrina del Cuerpo Místico son los más relevantes en nuestro autor? ¿Qué aspectos de la teología del Cuerpo Místico de Cristo se impusieron en su pensamiento para que pasara de una eclesiología a una antropología desde Cristo? ¿Cómo unas categorías teológicas terminaron iluminando su pensamiento social?

San Alberto expone el núcleo de la doctrina del Cuerpo Místico de Cristo con bastantes similitudes en su Discurso en el Teatro Caupolicán, en Humanismo Social, en su Conferencia en Cochabamba y en Moral Social. Al comparar estos textos entre sí, se descubre claramente que el padre Hurtado rentiliza sus propios escritos que modifica de acuerdo con los destinatarios, a los contextos de su apostolado y también a la evolución de su pensamiento. Por otra parte, el mismo san Alberto reconoce la influencia de Columba Marmión. Lo que se ha podido investigar con más detalle es la confrontación directa de los textos de Columba Marmión presente en algunos capítulos de su libro Cristo, vida del alma, comparándolos con estos textos de san Alberto.

La revisión de estos textos puede articularse en tres grandes temas: el ser auténticos hijos de Dios (2.1), la encarnación del Verbo y sus consecuencias para la humanidad (2.2), y la comunión de los santos en la unidad en Cristo (2.3). Estos se encuentran en paralelo con el texto de Abad de Maredsous: el tema de la filiación divina está en conexión con el capítulo I de Cristo, Vida del alma sobre el plan divino de nuestra filiación adoptiva en Jesucristo ${ }^{29}$. El tema de la encarnación del Verbo y sus consecuencias para la humanidad tiene una directa conexión con el capítulo XI de Cristo,

28 Cf. M. Clavero, «Un punto de inflexión en la vida del Padre Alberto Hurtado. Itinerario y balance de su viaje a Europa de 1947», Teología y Vida XLVI (2005) 291-320.

29 C. Marmión, Jesucristo, vida del alma. Conferencias espirituales (Santiago 1991) 3-31. 
Vida del alma dedicada al amor fraterno ${ }^{30}$. La comunión de los santos y la unidad en Cristo, san Alberto se inspira en el capítulo V de Cristo, Vida del alma que trata de la Iglesia como Cuerpo Místico de Cristo ${ }^{31}$.

\subsection{Auténticos hijos de Dios}

La autenticidad de la filiación adoptiva es una verdad que san Alberto considera muy relevante. En el año 1943, desde la publicación de Mystici Corporis Christi, insiste en la centralidad del estar llamados a ser hijos de Dios. Señala que «solo siéndolo llegará a ser plenamente hombre» ${ }^{32}$. Es decir, la plenitud humana no es otra que acoger la gracia de la filiación adoptiva. En un retiro sobre el Cuerpo Místico afirma que «la primera idea de ser cristiano significa, es darnos cuenta de que somos auténticos bijos de Diosi3. Entre los años 1943 a 1947 se encuentran otras alusiones que muestran su interés en afirmar la autenticidad y la verdad de la gracia de ser hijos de Dios ${ }^{34}$.

\section{a. El mensaje fundamental del cristianismo}

En el capítulo primero de Humanismo Social, al explicar la doctrina del Cuerpo Místico de Cristo como fundamento teológico de la caridad, comienza con un resumen del cristianismo:

El cristianismo en sus fundamentos es el mensaje de la divinización del hombre, de su liberación del pecado, de su vuelta a la gracia, de la adquisición del título y realidad de hijo de Dios ${ }^{35}$.

Sintetiza el fundamento del cristianismo en la divinización del hombre, en la liberación del pecado y la vuelta a la gracia. Ahora bien, quiere destacar la realidad de ser hijo de Dios, no solo la adquisición del título. Se advierte la influencia de la teología de Dom Marmión y su acento en la filiación divina en Jesucristo y no solo en la liberación del pecado.

\footnotetext{
C. Marmión, Jesucristo, vida del alma, 405-423.

C. Marmión, Jesucristo, vida del alma, 98-115.

32 APH s54y16a.

33 APH s47y24.
}

34 Textos donde habla de auténticos hijos de Dios: Orientación fundamental del catolicismo, 1943, APH s25y04; APH s30y23; APH s31y01b; textos donde dice hijos de Dios de verdad: Orientación fundamental del catolicismo, 1943, APH s25y04; APH s30y23; APH s31y01b; APH s58y08; APH s30y05.

35 A. Hurtado, Humanismo Social, 28. Por su parte E. Mersch había escrito que en Cristo "quedan los hombres divinizados y constituidos hijos de adopción” (É. MERSCH, Cuerpo Místico y Moral, [Bilbao 1963], 164). 
En Moral Social (1952) no inserta este texto literalmente, sino que lo reelabora y amplía la explicación sobre la grandeza del hombre. Muestra esta grandeza a la luz de la razón natural y de la revelación cristiana ${ }^{36}$. En la reelaboración del texto demuestra una mayor profundización teológica:

Dios creó al hombre para hacerlo su amigo, su hijo adoptivo, para hacerle participar su propia naturaleza, para darle una felicidad eterna que fuera participación de la que Él goza, que es Él mismo ${ }^{37}$.

San Alberto destaca que Dios creó al hombre para hacerlo su bijo adoptivo. Este relieve se descubre a la luz de las acentuaciones del texto, ya que insiste en que de verdad absoluta, el hombre pasa a ser auténtico hijo de Dios por la redención ${ }^{38}$.

La revisión y análisis de estos párrafos de Moral Social permite descubrir que el padre Hurtado elabora una antropología teológica capaz de fundamentar desde Dios la grandeza del hombre. En el tema específico de la filiación adoptiva, por un lado, afirma que desde la creación del hombre, Dios quiere «hacerlo su amigo, su bijo adoptivo» ${ }^{39}$ y elevarlo a un fin sobrenatural. Más adelante afirma que después del «pecado de nuestros primeros Padres $\aleph^{40}$, Dios «escogió un segundo camino aún más maravilloso para elevar a todos los hombres, de todos los tiempos, a la participación de la vida divinas ${ }^{41}$. Por tanto, san Alberto en el año 1952 está argumentando desde una antropología que supone una sola finalidad sobrenatural en el hombre, en la creación y en la redención. De este modo, el padre Hurtado se sitúa en la línea de Henri De Lubac, que postula que el hombre no tiene dos fines, sino uno solo: el fin sobrenatural ${ }^{42}$.

\section{b. La realidad de ser auténticos bijos de Dios}

Otro texto relevante que incluirá en varios de sus escritos es el siguiente:

36 Cf. A. Hurtado, Moral Social: obra póstuma del Padre Alberto Hurtado (Santiago 2004) 203.

37 A. Hurtado, Moral Social, 203.

38 Cf. A. Hurtado, Moral Social, 203.

39 A. Hurtado, Moral Social, 203.

40 A. Hurtado, Moral Social, 203.

41 A. Hurtado, Moral Social, 203.

42 Cf. H. Mühlen, «La doctrina de la gracia» en H. Vorgrimler - R. VAnder Gucht (eds.), La teología en el siglo XX, vol. III (Madrid 1973) 138-140. 
Por la redención podemos en realidad absoluta de verdad ser auténticos hijos de Dios, hermanos del Verbo, templos del Espíritu Santo. Nuestra incorporación a Cristo nos autoriza a llamar a Dios con toda certeza Padre nuestro ${ }^{43}$.

Destaca que el ser hijos de Dios es una realidad absoluta, que es de verdad, que la filiación de parte de Dios hace auténticos hijos de Dios por la redención. Por esto añade que la incorporación a Cristo autoriza para llamar a Dios Padre nuestro. Tal como se dijo antes, Dom Marmion centra su reflexión teológica en la adopción divina. San Alberto bebe de esta fuente y la profundiza con estos textos propios.

En su Conferencia en Cochabamba inserta este mismo texto. Sostiene que la dignidad del hombre no solo radica en el orden natural, sino sobre todo en el orden sobrenatural, ya que el hombre por la gracia «pasa a ser hïjo de Dios, heredero del cielo» ${ }^{44}$.

En Moral Social integra este texto con algunas modificaciones, entre ellas, suprimiendo la frase «nuestra incorporación a Cristo nos autoriza». Ahora bien, conserva esta acentuación de la verdad del ser auténticos hijos de Dios. Llega a decir que «quienes desde los albores de la creación han creído y esperado en Él, a la manera que esto les era posible según la luz recibida han pasado a ser de verdad bijos auténticos de Dios $\rangle^{45}$. Por tanto, el ser hijo de Dios es una posibilidad abierta a todo hombre. En esto se encuentra parte del fundamento antropológico de su dignidad. El ser auténticos hijos de Dios es una gracia a la cual está llamado todo hombre y «es imposible pensar en un don de mayores proporciones $\rangle^{46}$.

\subsection{La encarnación del Verbo y sus consecuencias para la bumanidad}

En nuestro estudio se han podido encontrar los párrafos de Columba Marmión que el padre Hurtado cita literalmente. En la transcripción, nuestro autor inserta algunas frases propias que dan cuenta de sus propias acentuaciones teológicas.

\footnotetext{
43 A. Hurtado, Humanismo Social, 29.

44 A. Hurtado, Cuerpo Místico: Distribución y uso de la riqueza, 1950, APH s24y09 (en A. Hurtado, La búsqueda de Dios, 152).

45 A. Hurtado, Moral Social, 203.

46 A. Hurtado, Moral Social, 203.
} 


\section{a. La pertenencia al Cuerpo Místico de Cristo}

Dom Marmion da cuenta en sus textos de la tensión en la pertenencia a Cristo y a su Cuerpo Místico. Habla de la unión a Cristo de derecho y de hecho, que solo los condenados quedan separados de esa unión, que hay que amar a los que pertenecen o pueden pertenecer al Cuerpo Místico de Cristo. San Alberto acoge y profundiza esta tensión sobre la pertenencia al Cuerpo Místico de Cristo.

En Humanismo Social (1947) redacta de esta forma la tesis del abad de Maredsous, que san Alberto hace suya:

Desde la encarnación y por la encarnación todos los hombres estamos unidos de derecho a Cristo y muchos de hecho ${ }^{47}$.

Escribe este texto cuando ya se había encontrado con el mendigo el año 1944 que lo impulsó a fundar el Hogar de Cristo ${ }^{48}$. La tensión en la pertenencia al Cuerpo Místico refleja un problema teológico y a la vez práctico: ¿'Todos pertenecen a Cristo? ¿Solo los bautizados? Al acoger a un pobre en el Hogar de Cristo, ¿se le pregunta si está bautizado? ¿El no bautizado pertenece a Cristo y a su Cuerpo Místico? Son estas preguntas las que le inquietan. ¿Cómo responder a ellas desde la teología?

San Alberto, que ha seguido literalmente el texto de Columba Marmión, introduce estas afirmaciones originales:

[Cristo] ha venido a ser la cabeza de un cuerpo, el Cuerpo Místico cuyos miembros somos o estamos llamados a serlo nosotros los hombres, sin limitación alguna de razas, cualidades naturales, fortuna, simpatías ${ }^{49}$. Basta ser hombre para poder ser miembro del Cuerpo Místico de Cristo, esto es, para poder ser Cristo ${ }^{50}$.

El padre Hurtado afirma que algunos miembros son y otros están llamados a serlo, añadiendo que esta llamada es para los hombres sin limitación de ningún tipo. Cuando llega a sostener que «basta ser hombre para poder ser miembro del Cuerpo Místico de Cristo, para poder ser Cristo», en-

\footnotetext{
A. Hurtado, Humanismo Social, 29. El subrayado es nuestro.

48 Cf. S. Fernández, «Circunstancias de la fundación del Hogar de Cristo. Estudio histórico de los documentos contemporáneos», Teología y Vida, XLIX (2008) 875-891.

49 A. Hurtado, Humanismo Social, 30.

50 A. Hurtado, Humanismo Social, 30; y Cuerpo Místico: Distribución y uso de la riqueza, 1950, APH s24y09 (en A. Hurtado, La búsqueda de Dios, 151); A. Hurtado, Moral Social, 204.
} 
Teología del Cuerpo Místico, antropología y moral social en san Alberto Hurtado | 595

contramos uno de los relieves teológicos que resalta nuestro autor. Sin duda la pertenencia al Cuerpo Místico de Cristo es un tema eclesiológico. Sin embargo, nuestro autor va integrando esta doctrina del Cuerpo Místico de Cristo como fundamento antropológico de la moral social.

En 1950, en su Conferencia en Cochabamba, la mayor comprensión de la grandeza del hombre viene del hecho de que, al sacar las consecuencias de la doctrina del Cuerpo Místico para la distribución de los bienes, sostiene que la primera consecuencia es la dignidad de la persona humana. Esta dignidad del hombre proviene del orden natural y «mucho más de su elevación al orden sobrenaturabi ${ }^{51}$. El paso hacia adelante es que no reflexiona sobre la grandeza del hombre de modo tangencial como en escritos anteriores, sino que la primera consecuencia de la doctrina del Cuerpo Místico es la dignidad del hombre.

En 1952, san Alberto afirma que «el hombre es el centro de la moral sociali, ${ }^{52}$. En la sección de Moral Social dedicada al hombre, profundizará en la comprensión de la grandeza de este. Primero, desde la razón natural y luego, desde la revelación cristiana. En este contexto introduce los textos que explican la doctrina del Cuerpo Místico de Cristo. En su reflexión sobre los miembros del Cuerpo Místico que ya son y los que están llamados a serlo, agrega sobre los llamados a serlo: «sin limitación alguna de razas, de fortuna, ni de otra alguna consideración ${ }^{53}$. Si antes en Humanismo Social y en su Conferencia en Cochabamba había hablado de la ausencia de limitaciones de cualidades naturales o simpatías, en Moral Social habla de la ausencia de cualquiera otra consideración. Por tanto, termina por universalizar al máximo el que todos los hombres están llamados a ser miembros del Cuerpo Místico de Cristo.

Para la teología moral social es relevante qué eclesiología está en la base de su reflexión. Teniendo esto presente, distintos autores consideran que la teología moral social como disciplina ha comenzado con el Concilio Vaticano $\mathrm{II}^{54}$. La eclesiología del Vaticano II es la comprensión de la Igle-

51 A. Hurtado, Cuerpo Místico: Distribución y uso de la riqueza, 1950, APH s24y09 (en A. Hurtado, La búsqueda de Dios, 156).

52 A. Hurtado, Moral Social, 202.

53 A. Hurtado, Moral Social, 204.

54 Cf. V. Gomez Mier, La Refundación de la Moral Católica. Cambios de matriz disciplinar después del Concilio Vaticano II (Estella 1995); J. QuerejAzu, «La teología moral social postvaticana. Génesis e instancias», Moralia, XVI (1993) 261-294. 
sia como Pueblo de Dios. Así se dan distintos niveles de pertenencia a este Pueblo de Dios, al que todos los hombres están llamados a pertenecer. Este presupuesto permite elaborar una teología moral social, basada en la dignidad de todo ser humano. En el siglo XX se ha pasado de una eclesiología que comprendía la Iglesia como sociedad perfecta, con un acento en lo jurídico, a una eclesiología que comprende la Iglesia como Pueblo de Dios. En este desarrollo histórico, la eclesiología de la Iglesia como Cuerpo Místico de Cristo ha tenido gran importancia ${ }^{55}$. La reflexión eclesiológica entre las dos guerras mundiales se centra en redescubrir la Iglesia en su misterio y la función de Cristo en ella ${ }^{56}$. El problema de la pertenencia a la Iglesia Cuerpo Místico de Cristo se presenta así como decisivo: si todos los hombres están llamados a pertenecer al Cuerpo Místico, tienen una dignidad desde Cristo que debe ser respetada. Por este camino el padre Hurtado llega a este principio permanente para la teología moral social.

Esta visión de la universalidad de la Iglesia a partir de la teología del Cuerpo Místico de Cristo muestra a nuestro autor en la línea de la eclesiología del Concilio Vaticano II. Lumen gentium trata el tema de los distintos niveles de pertenencia a la Iglesia en LG 14-17. Por otra parte el Concilio señala que «todos los hombres están invitados al Pueblo de Dios» ${ }^{57}$. Patricio Miranda comenta que en el tema de la pertenencia al Cuerpo Místico de Cristo, san Alberto refleja una «buella de anticipaciones conciliares» ${ }^{58}$.

Por otra parte, en estos escritos de san Alberto y en su progresiva comprensión de la grandeza del hombre se puede vislumbrar la cercanía de su pensamiento con otras afirmaciones del Concilio Vaticano II. En Gaudium et spes se dice que «el misterio del hombre sólo se esclarece en el misterio del Verbo encarnado» ${ }^{59}$, que «Cristo manifiesta plenamente el hombre al propio hombre y le descubre la grandeza de su vocación $\rangle^{60}$ y que «el Hijo de Dios, con su encarnación, se ha unido, en cierto modo, con todo hombres ${ }^{61}$. El padre Hurtado ha llegado

55 Cf. I. Camacho, Doctrina social de la Iglesia. Una aproximación bistórica (Madrid 1991) 297-302.

56 Cf. J. FrisQue, «La eclesiología en el siglo XX», 164-175.

57 Concilio Vaticano II, Lumen Gentium, 13.

58 Miranda, «Preludios del aggiornamento de la Moral Social en América Latina», 172.

59 Concilio Vaticano II, Gaudium et spes, 22.

60 Concilio Vaticano II, Gaudium et spes, 22.

61 Concilio Vaticano II, Gaudium et spes, 22. 
en su recorrido teológico a afirmar la dignidad de todo hombre desde la encarnación del Verbo.

\section{b. La presencia de Cristo en los pobres}

En Humanismo Social (1947) sigue muy de cerca el texto de Columba Marmión. Sin embargo, añade una frase propia muy importante para su pensamiento teológico y social, y para su apostolado: «debemos ver en los pobres a Cristor:

Por la fe debemos ver en los pobres a Cristo y si no lo vemos, es porque nuestra fe es tibia y nuestro amor imperfecto. Por esto San Juan nos dice: si no amamos al prójimo a quien vemos ¿cómo podremos amar a Dios a quien no vemos? Si no amamos a Dios en la forma visible ¿Cómo podremos decir que le amamos en sí mismo? ${ }^{62}$.

Donde Columba Marmión había escrito «por la fe, le vemos así en sus miembros», san Alberto escribe «por la fe debemos ver en los pobres a Cristo». Los pobres que se acogen en el Hogar de Cristo deben ser vistos como otro Cristo por la $\mathrm{fe}^{63}$. Señala que las condiciones para ver a Cristo en los pobres son la fe y el amor. La fe es la que hace posible el ver a Cristo en los pobres, por eso el no verlo se debe a una fe tibia. Una fe encendida es una de las condiciones que hacen posible el ver a Cristo en los pobres. La otra condición es un amor verdadero, pues si no se ve a Cristo en los pobres es porque hay un amor imperfecto. En este contexto se cita el texto de 1Jn que relaciona el ver y el amor, tanto a Dios como al prójimo.

En su Conferencia en Cochabamba esboza soluciones a la injusta distribución de los bienes. Estas soluciones son morales y también técnicas. Parte de la solución al problema de la injusta distribución de los bienes es ver a Cristo en los pobres. Escribe en este contexto:

Mientras los católicos no hayamos tomado en serio el dogma del Cuerpo Místico de Cristo que nos hace ver al Salvador en cada uno de nuestros hermanos, aun en el más doliente, en el más embotado

62 A. Hurtado, Humanismo Social, 31 y A. Hurtado, Cuerpo Mistico: Distribución y uso de la riqueza, 1950, APH s24y09 (en A. HurTAdo, La búsqueda de Dios, 152). El subrayado es nuestro.

63 Lo recuerda en un artículo para El Mercurio el 22 de octubre de 1944: "Cristo en la persona de muchos pobres no tiene casa" (APH s10y01). En otro artículo, publicado por El Diario Ilustrado el 17 de diciembre de 1944, señala: "El Hogar de Cristo aspira a dar posada el peregrino, con el mismo cariño y el mismo respeto con que se la daría a Cristo a quien los pobres representan" (APH s10y02). 
minero que masca coca, en el trabajador que yace ebrio, tendido física y moralmente por su ignorancia, mientras no veamos en ellos a Cristo nuestro problema no tiene solución ${ }^{64}$.

Se dirige a los católicos que están participando de este encuentro organizado por el episcopado boliviano. Les dice que tomen en serio el dogma del Cuerpo Místico de Cristo para ver a Cristo, el Salvador, en los pobres. En este caso Cristo se presenta bajo la forma de un doliente, de un minero que masca coca, de un trabajador ebrio. El padre Hurtado está convencido de que parte de la solución a la injusta distribución de los bienes se encuentra en ver a Cristo en los pobres. En esta última etapa de su vida, donde centra su reflexión en la dignidad de la persona humana, es decir de todo hombre, mantiene esta preferencia por la presencia de Cristo en el pobre. La opción preferencial por los pobres encuentra en estas reflexiones un anticipo profético.

En Moral Social (1952) sustituye su afirmación de «ver en los pobres a Cristo» por ver «a Cristo en el hombre que codeamos a cada momento». El texto de Moral Social queda así:

Si no vemos a Cristo en el hombre que codeamos a cada momento es porque nuestra fe es tibia y nuestro amor imperfecto. Por esto San Juan nos dice: si no amamos al prójimo a quien vemos ¿cómo podremos amar a Dios a quien no vemos? ${ }^{35}$.

La sustitución de pobre por hombre puede explicarse de la siguiente manera. La convicción de la presencia de Cristo en el pobre lo acompañó hasta sus últimos días. Cuando escribe sobre el Hogar de Cristo en su última enfermedad, sigue insistiendo que el pobre es Cristo. Ahora bien, en el contexto de Moral Social, está tratando sobre la grandeza del hombre y su dignidad como persona a partir de la creación y del orden sobrenatural, por esto insiste más en la dignidad de todo hombre en general.

\subsection{La unión de todos los hombres en Cristo y la comunión de los santos}

San Alberto habla en sus escritos iniciales de la unidad de los cristianos en Cristo. Luego, progresivamente va poniendo el acento en que esta unidad en Cristo abarca a todos los hombres. Desde su Discurso en el Teatro Caupolicán

\footnotetext{
${ }^{64}$ A. Hurtado, Cuerpo Místico: Distribución y uso de la riqueza, 1950, APH s24y09 (en A. Hurtado, La búsqueda de Dios, 156).

65 A. Hurtado, Moral Social, 204. El subrayado es nuestro.
} 
Teología del Cuerpo Místico, antropología y moral social en san Alberto Hurtado | 599

hasta Moral Social los ejemplos de diversidad de hombres apuntan a la universalidad de esta unidad en Cristo.

En 1943 san Alberto en su Discurso en el Teatro Caupolicán como Asesor de la Acción Católica reflexiona sobre la unidad en Cristo. Repite varias veces que «todos somos uno en Cristo». En esta afirmación encuentra una solución cristiana a las divisiones que vive en ese momento el mundo: «Proletarios y no proletarios, hombres todos de la tierra, ingleses y alemanes; italianos, norteamericanos, judios, japoneses, chilenos y peruanos reconozcamos que somos uno en Cristo y que nos debemos no el odio, sino que el amor que el propio cuerpo tiene a sí mismo» ${ }^{66}$. La unidad de todos en Cristo debe vencer la división entre proletarios y no proletarios, la llamada cuestión social. La unidad de todos en Cristo debe triunfar sobre los horrores de la Segunda Guerra Mundial, donde luchaban ingleses, alemanes, italianos, norteamericanos y japoneses, donde se perseguía a los judíos. San Alberto también descubre en la unidad de todos en Cristo la solución a las tensiones entre chilenos y peruanos.

En 1952 en Moral Social, incluye el texto recién aludido, añadiendo ejemplos concretos del alcance de la unidad de todos en Cristo: «americanos y rusos, japoneses y chinos, proletarios e industrialess ${ }^{67}$. La unidad en Cristo ilumina el conflicto de la Guerra Fría que ya se vivía en esos años entre americanos y rusos. La unidad en Cristo es capaz de acabar con divisiones milenarias entre japoneses y chinos. La unidad en Cristo es capaz de solucionar el conflicto entre proletarios e industriales. En conclusión, san Alberto piensa que con esta categoría teológica de la unidad en Cristo, se encuentra una solución desde la doctrina del Cuerpo Místico de Cristo a divisiones y conflictos de cada momento histórico.

La afirmación de san Alberto sobre la unidad de todos los hombres en Cristo lo inserta nuevamente en la renovación teológica que se verá reflejada en el Concilio Vaticano II. La afirmación de la Lumen Gentium de que «la Iglesia es en Cristo como un sacramento o signo e instrumento de la unión intima con Dios y de la unidad de todo el género humano» ${ }^{68}$ muestra a la teología del padre Hurtado como anticipadora del Concilio. En los años 40 y hacia el final de su vida está convencido de que la unidad en Cristo abarca a

\footnotetext{
${ }_{66}$ APH s19y27 (en A. Lavín, El Padre Hurtado, amigo y apóstol de los jóvenes, Santiago 1978, 54).

67 A. Hurtado, Moral Social, 204.

68 Concilio Vaticano II, Lumen Gentium, 1.
} 
todos los hombres, ya que basta ser hombre para poder ser miembro del Cuerpo Místico de Cristo.

El pensamiento del padre Hurtado se desarrolla también en torno a la categoría comunión de los santos. El Cuerpo Místico de Cristo implica la unidad de todos los hombres en Cristo y esta unidad es la comunión de los santos, dogma de la fe. La comunión de los santos es la participación en los méritos de María Santísima y de los santos, es la participación en los bienes y en los males de todos, es la participación en la gracia y en las plegarias de todos. Un aspecto que san Alberto destaca son los vínculos que existen por esta comunión:

La comunión de los santos nos hace entender que hay entre quienes formamos «la familia de Dios» vínculos mucho más íntimos que los de la camaradería, la amistad, los lazos de familia ${ }^{69}$.

Los vínculos que existen por la comunión de los santos son de orden sobrenatural, por eso son más intimos que los vínculos naturales de la camaradería, de la amistad, de los lazos familiares y de la clase social. Estos vínculos se deben a la gracia de Dios: el hombre en Cristo está unido a todos los demás hombres. Compara la comunión de los santos con los vínculos de la camaradería en un contexto polémico con el comunismo. Por esto afirma que «no somos camaradas, somos hermanos». Esta comunión de los santos, vivida de verdad, está llamada a triunfar sobre la internacional comunista, que proclama la unidad de una clase social para luchar contra otra.

La solidaridad social es definida desde la doctrina del Cuerpo Místico de Cristo. Para el padre Hurtado, quien comprende esta teología entiende la solidaridad social como aquella que refleja los vínculos sobrenaturales que existen entre los hombres por la comunión de los santos ${ }^{70}$. El fundamento antropológico de la solidaridad social se encuentra en el hombre vinculado con los demás desde Cristo.

\section{Algunas conclusiones}

\subsection{La dignidad de la persona bumana}

San Alberto ha pensado en el hombre desde el misterio de Cristo. Nos ha llevado desde la eclesiología del Cuerpo Místico a una antropología desde

\footnotetext{
69 A. Hurtado, Humanismo Social, 32.

70 Para la dimensión social de la comunión de los santos, cf. F. PARRA, Contexto teológico del pensamiento social del padre Hurtado (Pro manuscripto), 79-80.
} 
Cristo, capaz de fundamentar una moral social. El punto de madurez de su pensamiento teológico ha sido la elaboración sistemática de una moral social. En esta moral social el hombre ocupa el lugar central. ¿En qué se sustenta este lugar central de la persona? En la dignidad que le viene del orden natural y sobre todo del orden sobrenatural: «La riqueza de nuestra doctrina social reside entera en el principio de la dignidad de la persona bumana en el orden natural y mucho más en su elevación al orden sobrenaturab $7^{71}$. Cuando argumenta desde el orden natural, el padre Hurtado sostiene que el hombre es persona, unidad de cuerpo y alma, y sujeto de derechos y deberes ${ }^{72}$. Cuando argumenta desde el orden sobrenatural recurre a la teología del Cuerpo Místico. En primer lugar, si todo hombre está llamado a ser hijo de Dios, entonces el hombre posee una dignidad propia. En segundo lugar, si basta ser hombre para poder pertenecer a Cristo y a su Cuerpo Místico, entonces todo hombre debe ser respetado. La dignidad del hombre se fundamenta desde Cristo, desde su encarnación.

El libro Moral Social es el punto de llegada de muchos años de reflexión sobre lo social, a través de las categorías teológicas de la doctrina del Cuerpo Místico, que en sus palabras ocupa «el primer lugar en nuestra posición teológicas ${ }^{73}$. En su obra póstuma da cuenta de unos presupuestos teológicos y antropológicos. En su antropología teológica se hace patente una elaboración más profunda que en textos anteriores. Su convicción del año 1943 de que solo siendo hijo de Dios el hombre llega a su plenitud, es desarrollada con mayor hondura en Moral Social. El padre Hurtado afirma que en la creación el plan de Dios es llamar al hombre a su amistad y a la filiación por gracia. El pecado original no arruina el proyecto de Dios, ya que por la redención, Cristo eleva nuevamente al hombre al don de ser auténtico hijo de Dios. Este es un don de mayores proporciones. En esta antropología burtadiana se descubre una comprensión unitaria del fin sobrenatural del hombre. El ser humano no tiene dos fines, uno natural y otro sobrenatural, sino un solo fin: la amistad y la filiación adoptiva como don. Es decir, el hombre llega a su plenitud cuando vive su ser hijo auténtico de Dios. Se descubre una concepción de la gracia de características más personalistas, ya que Dios llama a ser amigo e hijo. Ahora bien, también se encuentra

\footnotetext{
71 A. Hurtado, Cuerpo Místico: Distribución y uso de la riqueza, 1950, APH s24y09 (en A. Hurtado, La búsqueda de Dios, 156).

72 Cf. A. Hurtado, Moral Social, 203.

73 A. Hurtado, Cuerpo Místico: Distribución y uso de la riqueza, 1950, APH s24y09 (en A. Hurtado, La búsqueda de Dios, 150).
} 
en Moral Social una definición clásica de gracia como «participación creada del ser divino que nos viene de Cristo como de su fuentes ${ }^{74}$. Da la impresión de que la concepción más escolástica en esta última definición de la gracia se complementa con la visión más personalista de Dios que llama al hombre a ser su amigo y su hijo adoptivo.

¿De dónde arranca la universalidad de la dignidad humana? San Alberto responde que ciertamente del orden natural, pero mucho más del orden sobrenatural. La dignidad de la persona humana arranca del llamado de todo hombre a ser hijo de Dios y de que basta ser hombre para pertenecer a Cristo y a su Cuerpo Místico. Todo esto como consecuencia de la encarnación del Verbo. Ha tomado en serio el pensar al hombre desde Cristo.

Javier Querejazú afirma que con el Concilio Vaticano II «la moral social encuentra la oportunidad de constituirse con solvencia y plenitud en saber teológico» ${ }^{75}$. Este autor hace notar la diferencia con los manuales de moral prevaticana de corte más casuista, y con la doctrina social de la Iglesia, que privilegiaba una aproximación de filosofía cristiana más que de teología. Javier Querejazú expresa el desafío postvaticano de que la moral social se configure con categorías más teológicas como la creación, el pecado, la encarnación, la redención y la escatología ${ }^{76}$.

Cuando revisamos el camino recorrido por san Alberto y su punto de llegada en la elaboración de una moral social, resulta impresionante constatar que su pensamiento estaba en la senda del Concilio Vaticano II. En primer lugar, el padre Hurtado concibe la moral social desde presupuestos teológicos y antropológicos. El Concilio afirma que el misterio del hombre solo se ilumina a la luz del Verbo encarnado ${ }^{77}$. El padre Hurtado, algunos años antes de este Concilio, quiso sacar todas las consecuencias de la encarnación del Verbo y encontró un fundamento para la dignidad de la persona humana desde Cristo. Se puede afirmar que la antropología de Moral Social es una comprensión del hombre desde las categorías de la creación, el pecado, la encarnación, la redención y la escatología, como sugiere Querejazú sobre moral social y su relación con el Vaticano II.

\footnotetext{
74 A. Hurtado, Moral Social, 393.

75 J. Querejazu, «La teología moral social postvaticana. Génesis e instancias», 269.

76 Cf. J. Querejazu, «La teología moral social postvaticana. Génesis e instancias», 270.

77 Cf. Concilio Vaticano II, Gaudium et spes, 22.
} 
La moral social, al presentar la dignidad de todo hombre, pretende proponer una ética social en diálogo con los no creyentes. Esta universalidad de la dignidad humana se hace necesaria. Ahora bien, al encontrar el fundamento antropológico en Cristo, ¿se puede proponer a los no cristianos? Esta tensión nos remite al diálogo fe y razón. Una convicción de fe, la visión del hombre desde Cristo, necesita encontrar en la razón argumentos que legitimen una universalidad en la dignidad humana. El debate sobre la especificidad de la moral cristiana encuentra en este tema uno de sus capítulos ${ }^{78}$. Hay que dialogar y comunicar la ética social cristiana y al mismo tiempo hacer patente los contenidos específicos que se descubren desde el misterio de Cristo.

En conclusión, el padre Hurtado ha pensado teológicamente en el hombre a partir de las categorías de la doctrina del Cuerpo Místico de Cristo. En el orden natural y sobre todo en el orden sobrenatural ha encontrado argumentos para fundamentar antropológicamente una moral social. Esto lo ha hecho transitar, en calidad de precursorprofético, por las mismas sendas que el Concilio Vaticano II y la teología moral social pos vaticana.

\subsection{El pobre es Cristo}

Esta convicción de la presencia de Cristo en el pobre es para san Alberto una consecuencia social de la teología del Cuerpo Místico de Cristo. Ciertamente ha sido una clave hermenéutica en su pensamiento teológico y social. Podemos decir que se ha dado un círculo hermenéutico en esta convicción de que el pobre es Cristo. Primero, el padre Hurtado acogió la doctrina del Cuerpo Místico, específicamente la presencia de Cristo en el que sufre. En este contexto teológico se encuentra con el mendigo, que significó para él un verdadero encuentro con Cristo. La fundación del Hogar de Cristo con la acogida a los pobres, bautizados o no, volvió a motivar la reflexión teológica de nuestro autor. La experiencia incide en su reflexión teológica. Por tanto, el círculo hermenéutico reflexión-experiencia-reflexión potencia un desarrollo en su pensamiento. Ciertamente después de su viaje a Europa el centro de la reflexión teológica fue la dignidad de todo hombre, fundamento para una ética social. Pero, ¿pasó de afirmar que el pobre es Cristo a que el pobre es hombre y así fundamentar una moral social? Si bien hemos demostrado la centralidad de la dignidad de todo hombre para fundamentar una moral social, en nuestro autor no hay una

78 Cf. T. TRIgo, El debate sobre la especificidad de la moral cristiana, (Navarra 2003). 
dialéctica de dar por superada una convicción anterior y abrirse a otra superando la anterior. El padre Hurtado fundamenta su moral social en la dignidad de todo hombre, pero no abandona la convicción de que el pobre es Cristo. En 1950 llega a afirmar que mientras los católicos no vean a Cristo en el pobre no hay solución a la injusta distribución de los bienes. La necesaria reforma de estructuras, basada en la dignidad de todo hombre, se complementa con esta categoría ético-social de la presencia de Cristo en el pobre.

El objetivo teológico de san Alberto era sacar todas las consecuencias a la encarnación del Verbo. Si Cristo se ha unido en principio a toda la humanidad en la encarnación, lo ha hecho de modo especial con los pobres. San Alberto reflexiona a partir principalmente del texto de $\mathrm{Mt}$ 25, 40. El pobre con el que se identifica Cristo es siempre concreto. Por esto nuestro autor no duda en hacer descripciones muy vivas como las que hace en Cochabamba. Para ver a Cristo en los pobres, se requiere una fe fuerte y una caridad intensa ${ }^{79}$. El padre Hurtado siempre insistió en la visión de fe y en la visión de eternidad para poder ser contemplativos. En la espiritualidad ignaciana encontró las claves para vincular la vida de oración con el compromiso social. Sobre la convicción de que el pobre es Cristo, Tony Mifsud comenta: «Este sentido del pobre [para san Alberto] sólo nace de la fe, se verifica (se hace verdad) en la práctica de la caridady la lucha por la justicia socialis ${ }^{80}$.

En la historia de la teología moral social, la categoría de la opción preferencial por los pobres es fundamental. Javier Querejazú sostiene que la teología de la liberación ha aportado a la teología moral social la opción preferencial por los pobres como «lugar ético-eclesiall y como «criterio moral preferente» ${ }^{81}$. Es decir el pobre está en el centro de la reflexión teológica y ética. El Magisterio latinoamericano ha hecho suya la opción por los pobres, en especial en las Conferencias de Medellín, Puebla y Santo Domingo. A nivel de Magisterio universal, ha sido el Papa Juan

79 Escribe: «No basta mirar al pobre con los ojos corporales: sólo muestran bajeza. Los que los contemplan con los ojos del alma iluminada por la fe descubren en él a Jesucristo, y ven en los pobres los herederos de sus promesas, los hijos verdaderos, más aún los dispensadores de su gracia (....). El que comprende verdaderamente el misterio de la caridad es el que considera a los pobres como a los primeros hijos de la Iglesia; el que honrando esta cualidad se cree obligado a servirles) (Los pobres, APH s57y13a).

80 T. Mifsud, El sentido social: el legado ético del padre Hurtado, 153.

81 J. Querejazu, «La teología moral social postvaticana. Génesis e instancias», 281. 
Pablo II quien ha profundizado en las implicancias éticas de la opción o amor preferencial por los pobres ${ }^{82}$. Luego, la Conferencia de Aparecida, a propósito de esta opción por los pobres, dice: que «está implícita en la fe cristológica», que los cristianos están llamados a «contemplar, en los rostros sufrientes de nuestros hermanos, el rostro de Cristo que nos llama a servirlo en ellos,, que el fundamento bíblico para vincular a Cristo y los pobres es Mt 25, 40 y por último que «Juan Pablo II destacó que este texto bíblico "ilumina el misterio de Cristo" ${ }^{83}$.

A la luz de la importancia del pobre para la teología moral social, el aporte de la teología de san Alberto es relevante. Su reflexión teológica, en circularidad hermenéutica con su experiencia y apostolado, ha llegado a la convicción de la presencia de Cristo en los pobres. Esta convicción está llamada a ocupar un lugar en la vida social y en la moral social. La experiencia, por tanto, incide en su reflexión teológica. Por otra parte, la caridad y la justicia social deben está marcadas por esta presencia de Cristo en el pobre. Aquí hay una antropología teológica que mira no solo al hombre en general, sino sobre todo al pobre de modo particular. El problema social no tiene solución si no se mira desde la opción de Cristo por los pobres. Por su propio camino teológico, el padre Hurtado ha llegado a coincidir con lo que señala el documento de Aparecida: contemplar a Cristo en los pobres y servirlos. El fundamento se encuentra en las palabras de Cristo (Mt 25, 40) y en una profundización del misterio cristológico. El aporte de san Alberto desde la teología del Cuerpo Místico es significativo. Dice Jorge Costadoat que «por medio de la identificación de Cristo con el pobre, inspirada una y otra vezpor la parábola evangélica del Juicio Final, el padre Hurtado se anticipa proféticamente a la "opción por los pobres" de la Iglesia latinoamericana en sus conferencias de Medellín, Puebla y Santo Domingo» ${ }^{84}$.

\subsection{La solidaridad social}

San Alberto se ha tomado en serio las verdades de la unidad en Cristo, de la comunión de los santos, de los vínculos sobrenaturales de la gracia y ha pensado la realidad social con estas categorías.

\footnotetext{
82 Cf. Juan Pablo II, Sollicitudo rei socialis, 42; Centesimus annus, 11.

83 Documento de Aparecida, 393.

84 J. Costadoat, «El talante social, en la espiritualidad del Hurtado», Cuadernos de Espiritualidad, XCIII (1995) 20.
} 
La naturaleza social del hombre explica toda la red de relaciones sociales que se dan en la historia de la humanidad. El padre Hurtado en su moral social tiene en cuenta esta sociabilidad humana que proviene de su naturaleza y de su ser personal en relación con los demás. Sin embargo, el aporte de nuestro autor está en haber pensado la vida social desde las verdades sobrenaturales. La unidad de todos los hombres en Cristo no es algo externo al hombre y a la sociedad. Esta unidad en Cristo es comunión entre los hombres y se manifiesta en vinculos más intimos que cualquier otro vínculo social, incluso los lazos de familia. San Alberto ha hecho teología de frente a la historia, por esto ha interpretado los conflictos y divisiones contemporáneas a la luz de la unidad en Cristo. La Segunda Guerra Mundial, la Guerra Fría y el conflicto trabajo y capital son iluminados por nuestro autor desde esta unidad de todos los hombres en Cristo, incluso los que aparecen enemigos y contrarios en la vida social concreta.

El contexto polémico en que reflexiona el padre Hurtado ha sido el de las ideologías del comunismo y del capitalismo. Frente al comunismo que postulaba la lucha de clases y llamaba a la unidad de los proletarios del mundo, nuestro autor llama a la unidad de proletarios e industriales desde la comunión en el Cuerpo Místico de Cristo. Frente al capitalismo que postula un individualismo y una superioridad del capital sobre el trabajo, nuestro autor llama a ver en el obrero o en el patrón la presencia de Cristo.

La catolicidad es la pretensión cristiana de universalidad. La Iglesia está llamada a incluir a todos, nadie debe quedar fuera de la salvación. San Alberto mira la realidad sobrenatural de la comunión de los santos, a María y a los santos y aplica esta solidaridad de la gracia a la realidad social, por esto habla de solidaridad social. En conclusión, en la sociedad se deben vivir en concreto los vínculos sobrenaturales de la gracia.

Para la historia de la teología moral social resulta fundante como disciplina científica el marco teológico del Concilio Vaticano II. La Iglesia en Cristo se hace instrumento de la unidad de todo el género humano ${ }^{85}$. La categoría comunión es clave para entender la eclesiología conciliar. Por otra parte, la Iglesia se manifiesta solidaria de todos los hombres ${ }^{86}$. Por último, en la Constitución Pastoral Gaudium et spes se desarrolla todo un capítulo

\footnotetext{
85 Cf. Concilio Vaticano II, Lumen gentium, 1.

86 Cf. Concilio Vaticano II, Gaudium et spes, 1.
} 
sobre la comunidad humana, a partir de la sociabilidad natural del hombre $^{87}$. El padre Hurtado se encaminaba por las categorías teológicas que maduraron en el Concilio Vaticano II: la unidad en Cristo de la Iglesia y en ella la unidad de todos los hombres, la comunión como vínculo sobrenatural con Dios y con los que pertenecen a la Iglesia.

La teología moral social ha desarrollado el tema del ser social del hombre y en particular la categoría solidaridad ha ido comprendiéndose cada vez con mayor profundidad. El Magisterio social del Papa Juan Pablo II ha hecho un aporte muy significativo en la comprensión de la solidaridad, especialmente en las encíclicas Sollicitudo rei socialis y en Centesimus annus. Su Santidad ha reflexionado sobre la solidaridad a partir de la sociabilidad natural de la persona humana y de la creciente interdependencia entre los hombres y los pueblos en el mundo contemporáneo. Se refiere también a la dimensión específicamente cristiana de la solidaridad. Además, se aproxima a la solidaridad desde el misterio trinitario, desde la unidad y comunión en Dios, desde unos vínculos más profundos que los naturales $^{88}$. En esta aproximación más teológica que hace el Santo Padre sobre la solidaridad, se descubre una clara sintonía con las reflexiones del padre Hurtado. Aunque el lenguaje es distinto, coinciden en las categorías teológicas de la unidad, la comunión y los vínculos sobrenaturales. Ciertamente la teología trinitaria del Santo Padre es más elaborada que la de nuestro autor, que reflexiona principalmente desde Cristo.

87 Cf. J. Querejazu, «La teología moral social postvaticana. Génesis e instancias», 129; Concilio Vaticano II, Gaudium et spes, 23-32.

88 La cita de Sollicitudo rei socialis, 40 es: «Entonces la conciencia de la paternidad común de Dios, de la hermandad de todos los hombres en Cristo, "hijos en el Hijo", de la presencia y acción vivificadora del Espíritu Santo, conferirá a nuestra mirada sobre el mundo un nuevo criterio para interpretarlo. Por encima de los vínculos humanos y naturales, tan fuertes y profundos, se percibe a la luz de la fe un nuevo modelo de unidad del género humano, en el cual debe inspirarse en última instancia la solidaridad. Este supremo modelo de unidad, reflejo de la vida íntima de Dios, Uno en tres Personas, es lo que los cristianos expresamos con la palabra "comunión"». 
Resumen: La teología del Cuerpo Místico de Cristo ocupó un lugar central en el pensamiento de san Alberto Hurtado. En las distintas etapas de su vida desarrolló una antropología a partir del Cuerpo Místico: el hombre está llamado a ser hijo de Dios, basta ser hombre para poder pertenecer al Cuerpo Místico, Cristo está presente en los pobres y la unidad de todos los hombres en Cristo. Este estudio muestra la influencia de Columba Marmión en nuestro autor. Esta antropología teológica es el fundamento de su moral social: la dignidad de la persona humana está fundamentada en la encarnación del Verbo. La opción por los pobres y la solidaridad social son parte de la ética social que el padre Hurtado ha fundamento con su teología del Cuerpo Místico de Cristo.

Palabras clave: san Alberto Hurtado, Cuerpo Místico, antropología, moral social.

Abstract: The theology of the Christ Mystical Body has occupied a principal place in St. Alberto Hurtado's thought. He developed an anthropology from the Mystical Body in the different moments of his life: the man is called to be a children of God, that is enough to be a man to be able to belong at de Mystical Body, that Christ is present in the poors, and the unity of all men in Christ. This investigation shows the influence of Columba Marmión in our author. The theological anthropology is the foundation of his social morality: the dignity of human person is based in the incarnation of the Word. The option for the poors and social solidarity are part of the social ethics that padre Hurtado has based with his theology of the Christ Mystical Body.

Keywords: saint Alberto Hurtado, Mystical Body, anthropology, social morality. 